\title{
Potensi Spons sebagai Media Alternatif Budidaya Sayuran dengan Sistem Hidroponik
}

\section{Potential of Sponge as an Alternative Medium for Vegetable Cultivation in Hydroponic System}

\author{
Tati Barus $^{1 *}$, Adrina Weisa ${ }^{2}$, Renna Eliana Warjoto ${ }^{3}$ \\ ${ }^{1}$ Master of Biotechnology, Faculty of Biotechnology, Universitas Katolik Atma Jaya, Jakarta 12930, Indonesia \\ ${ }^{2-3}$ Department of Biology, Faculty of Biotechnology, Universitas Katolik Atma Jaya, Jakarta 12930, Indonesia
}

Received 03 April 2020; Accepted 04 December 2020; Published 30 June 2021

\begin{abstract}
Several technologies are evolving with the increasing agricultural product demand. The use of hydroponic systems appears more common, where the growing medium serves as a significant factor in determining plant growth, without available information on the use of sponges. This study is aimed at obtaining information on the potential of sponges as a hydroponic media in water spinach (Ipomoea aquatica), pak choi (Brassica rapa) and kale (Brassica oleracea). The method used was a completely randomized design with three replications and the treatment comprised of three growing media types, termed sponges, local and imported rockwool. The result showed an improvement in the growth of water spinach and pak choi in sponges, compared to local and imported rockwool. Furthermore, kale was known to develop more extensively on the entire media but varied insignificantly in kale.
\end{abstract}

Keywords: Growth; Kale; Pak choi; Water Spinach

Cite this as (CSE Style): Barus T, Weisa A, Warjoto RE. 2021. Potensi spons sebagai media alternatif budidaya sayuran dengan sistem hidroponik. Agrotechnology Res J. 5(1):7-11. https://dx.doi.org/10.20961/agrotechresj.v5i1.40981.

\section{PENDAHULUAN}

Sayuran telah dilaporkan baik bagi kesehatan karena mengandung antioksidan yang dapat mencegah radikal bebas dalam tubuh (Ramya dan Patel 2019), sebagai sumber vitamin, mineral, serat dan fitokimia (Dias 2012). Sayuran juga kaya akan senyawa metabolit sekunder dan senyawa bioaktif yang dapat menurunkan berbagai jenis penyakit kronis seperti penyakit jantung dan kanker (Manchali et al. 2012; Wallace et al. 2020).

Indonesia merupakan salah satu negara dengan jumlah penduduk yang tinggi (tahun 2014 sekitar 250 juta jiwa) dengan laju pertumbuhan $\pm 1,49 \%$ /tahun (Badan Pusat Statistik 2015). Hal tersebut mengakibatkan peningkatan kebutuhan sayuran. Namun peralihan fungsi lahan pertanian menjadi perumahan, industri, perkantoran dan infrastruktur (Mulyani et al. 2016) menyebabkan berkurangnya luas lahan produktif untuk budidaya sayuran. Oleh sebab itu, perlu ada upaya untuk meningkatkan produksi sayuran guna memenuhi kebutuhan yang terus meningkat.

${ }^{*}$ Corresponding Author:

E-Mail: tati.barus@atmajaya.ac.id
Salah satu upaya untuk meningkatkan produksi sayuran pada lahan terbatas adalah budidaya dengan sistem hidroponik. Terdapat berbagai keuntungan budidaya tanaman secara hidroponik. Diantaranya penggunaan air dan nutrisi yang efisien dan terkontrol (Nguyen et al. 2016; Radhakrishnan et al. 2019), perawatan tanaman tergolong mudah, produksi dapat berkelanjutan, harga hasil produksi yang tinggi, dan tidak tergantung musim (Roidah 2014).

Salah satu faktor yang menentukan kualitas tanaman pada sistem hidroponik adalah jenis media tanam yang digunakan (Bachtiar et al. 2017; Radhakrishnan et al. 2019; Suryani et al. 2017). Media tanam hidroponik yang umum digunakan adalah rockwool lokal dan rockwool impor. Namun, media-media tersebut pada daerah tertentu sulit ditemukan dan harganya relatif mahal. Oleh sebab itu perlu dikaji media tanam hidroponik lain dengan harga murah dan mudah ditemukan seperti spons. Informasi tentang potensi spons sebagai media hidroponik belum tersedia. Oleh sebab itu, penelitian ini bertujuan untuk mengkaji tentang pengaruh penggunaan spons sebagai media tanam kangkung (Ipomoea aquatica), pakcoy (Brassica rapa) dan kale (Brassica oleracea) pada budidaya sistem hidroponik. 


\section{BAHAN DAN METODE}

Penelitian dilaksanakan di rumah kaca Fakultas Teknobiologi Universitas Katolik Indonesia Atma Jaya Cisauk, Tangerang pada bulan Januari-April 2019. Rancangan percobaan yang digunakan yaitu Rancangan Acak lengkap non faktorial. Perlakuan terdiri atas penggunaan media spons, media rockwool lokal dan media rockwool impor. Ketiga jenis media tanam tersebut dipotong dengan ukuran $2 \mathrm{~cm} \times 2 \mathrm{~cm} \times 2 \mathrm{~cm}$. Setiap perlakuan diulang 3 kali.

Pelaksanaan penelitian diawali dengan seleksi benih. Penyemaian langsung dilakukan pada media tanam yang digunakan (spons, rockwool lokal dan rockwool impor) dan selanjutnya dipindahkan ke perangkat hidroponik. Pakcoy dan kale ditanam satu tanaman per net pot, sementara kangkung ditanam tiga tanaman per net pot. Pemberian nutrisi (Tabel 1) dilakukan setelah ketiga jenis tanaman berada pada perangkat hidroponik, nutrisi yang diberikan berasal pupuk AB-mix.

Tabel 1. Konsentrasi nutrisi setiap fase pertumbuhan

\begin{tabular}{lccc}
\hline \multirow{2}{*}{$\begin{array}{l}\text { Umur } \\
\text { Hari) }\end{array}$} & \multicolumn{3}{c}{ Konsentrasi Nutrisi setiap Tanaman (ppm) } \\
\cline { 2 - 4 } & Kangkung & Pakcoy & Kale \\
\hline $01-07$ & 600 & 600 & 600 \\
$08-14$ & 900 & 600 & 600 \\
$15-20$ & 1200 & 900 & 900 \\
21 & panen & 900 & 900 \\
$22-31$ & - & 1200 & 1200 \\
32 & - & panen & 1200 \\
$33-41$ & - & - & 1200 \\
42 & - & - & panen \\
\hline
\end{tabular}

Keterangan: Umur (hari) adalah saat tanaman sudah berada di perangkat hidroponik (tidak termasuk umur tanaman saat penyemaian)

Parameter pertumbuhan sampel tanaman yang diamati terdiri atas tinggi, jumlah daun, bobot akar, bobot tajuk. Pengukuran tinggi tanaman hanya dilakukan terhadap kangkung dan kale. Jumlah daun yang dihitung adalah daun yang sudah terbuka sempurna. Pengamatan parameter pertumbuhan setiap tanaman dilakukan saat panen seperti tercantum pada Tabel 1.

Data hasil penelitian dianalisis menggunakan Analysis of Variants (ANOVA). Apabila perlakuan berbeda nyata maka dilanjutkan dengan uji perbandingan antar rataan perlakuan dengan Duncan Multiple Range Test (DMRT) dengan taraf kepercayaan $95 \%$.

\section{HASIL DAN PEMBAHASAN}

Budidaya sistem hidroponik merupakan salah satu sistem budidaya yang banyak diaplikasikan saat ini, khususnya sayuran. Jenis media tanam yang digunakan merupakan salah satu faktor yang menentukan pertumbuhan tanaman pada sistem budidaya hidroponik (Al-Raisy et al. 2010; Wahome et al. 2011; Haghighi et al. 2016). Hasil penelitian menunjukkan bahwa tanaman tumbuh dengan baik dalam sistem hidroponik. Hal ini karena air dan nutrisi tersedia selama pertumbuhannya. Air merupakan komposisi tertinggi dalam jaringan tanaman (Bozkurt et al. 2009; Nugraheni et al. 2019), penting untuk peristiwa evapotranspirasi (Bozkurt et al. 2009) dan pelarut pada berbagai reaksi biokimia dalam sel termasuk fotosintesis (Nugraheni et al. 2019). Air dan nutrisi merupakan faktor penting untuk proses fotosintesis yang merupakan reaksi untuk pembentukan makromolekul yang diperlukan bagi pertumbuhan tanaman (Nugraheni et al. 2019).

\section{Pertumbuhan kangkung}

Hasil penelitian menunjukkan bahwa kangkung dapat tumbuh dengan baik pada media spons, rockwool lokal dan rockwool impor. Tabel 2 menunjukkan bahwa ketiga jenis media pertumbuhan berpengaruh nyata terhadap pertumbuhan kangkung. Pertumbuhan kangkung terbaik pada media spons yaitu memiliki tinggi tanaman tertinggi $(84,05 \mathrm{~cm})$. Hasil tersebut berbeda nyata dengan tinggi kangkung pada media rockwool impor $(68,0 \mathrm{~cm})$. Demikian juga bobot akar kangkung terbesar ditemukan pada media spons $(0,5 \mathrm{~g})$ yang berbeda signifikan dengan bobot akar kangkung pada media rockwool lokal $(0,2 \mathrm{~g})$ dan rockwool impor $(0,3 \mathrm{~g})$. Media tanam spons, rockwool lokal dan rockwool impor masing-masing parameter jumlah daun dan bobot tajuk tidak berpengaruh nyata. Oleh karena itu maka pertumbuhan kangkung terbaik ditemukan pada media spons. Kangkung merupakan sumber serat pangan dan mineral $\mathrm{K}, \mathrm{Mn}$ serta Fe (Umar et al. 2007). Kangkung juga telah dilaporkan mengandung vitamin C yang bersifat antioksidan (Yang et al. 2014).

Tabel 2. Pertumbuhan kangkung pada tiga media yang berbeda

\begin{tabular}{lrrr}
\hline \multirow{2}{*}{ Peubah } & \multicolumn{3}{c}{ Media } \\
\cline { 2 - 4 } & Spons & \multicolumn{1}{c}{$\begin{array}{c}\text { Rockwool } \\
\text { Lokal }\end{array}$} & $\begin{array}{c}\text { Rockwool } \\
\text { Impor }\end{array}$ \\
\hline Tinggi $(\mathrm{cm})$ & $84,10 \pm 1,5 \mathrm{~b}$ & $73,8 \pm 1,5 \mathrm{ab}$ & $68,0 \pm 5,2 \mathrm{a}$ \\
Jumlah daun & $23,85 \pm 1,9 \mathrm{a}$ & $23,0 \pm 1,8 \mathrm{a}$ & $22,1 \pm 1,0 \mathrm{a}$ \\
Bobot akar $(\mathrm{g})$ & $0,50 \pm 0,1 \mathrm{a}$ & $0,2 \pm 0,1 \mathrm{~b}$ & $0,3 \pm 0,1 \mathrm{~b}$ \\
Bobot tajuk (g) & $12,00 \pm 1,8 \mathrm{a}$ & $9,0 \pm 1,4 \mathrm{a}$ & $9,3 \pm 0,5 \mathrm{a}$ \\
\hline
\end{tabular}

Keterangan: Angka yang diikuti oleh huruf yang sama pada baris yang sama menunjukkan tidak berbeda nyata menurut DMRT pada tingkat kepercayaan $95 \%$.

\section{Pertumbuhan pakcoy}

Hasil penelitian menunjukkan bahwa pakcoy tumbuh dengan baik pada media spons, rockwool lokal dan rockwool impor. Namun jenis media tanam spons, rockwool lokal dan rockwool impor berpengaruh nyata terhadap pertumbuhan tanaman. Tabel 3 menunjukkan bahwa pertumbuhan pakcoy terbaik ditemukan pada media spons. Media spons menghasilkan bobot akar pakcoy tertinggi $(9,3 \mathrm{~g})$ dan berpengaruh nyata dengan bobot akar pada media rockwool lokal $(4.8 \mathrm{~g})$ dan rockwool impor $(6.0 \mathrm{~g})$. Pada media spons ditemukan bobot tajuknya tertinggi $(140,3 \mathrm{~g})$ secara signifikan berbeda nyata dengan bobot tajuk pada media rockwool lokal (117,5 g). Parameter jumlah daun dan bobot tajuk media tanam spons, rockwool lokal dan rockwool impor tidak berpengaruh nyata. (Tabel 3). Dengan demikian maka pertumbuhan pakcoy terbaik ditemukan pada media spons. 
Tabel 3. Pertumbuhan pakcoy pada tiga media yang berbeda

\begin{tabular}{lrrr}
\hline Peubah & \multicolumn{3}{c}{ Media } \\
\cline { 2 - 4 } & Spons & $\begin{array}{c}\text { Rockwool } \\
\text { Lokal }\end{array}$ & $\begin{array}{c}\text { Rockwool } \\
\text { Impor }\end{array}$ \\
\hline Jumlah daun & $21,5 \pm 0,6 \mathrm{a}$ & $20,8 \pm 1 \mathrm{a}$ & $20,3 \pm 1,0 \mathrm{a}$ \\
Bobot akar $(\mathrm{g})$ & $9,3 \pm 1,0 \mathrm{~b}$ & $4,8 \pm 2,1 \mathrm{a}$ & $6,0 \pm 1,4 \mathrm{a}$ \\
Bobot tajuk(g) & $140,3 \pm 2,5 \mathrm{~b}$ & $117,5 \pm 3,3 \mathrm{a}$ & $142,8 \pm 2,5 \mathrm{~b}$ \\
\hline
\end{tabular}

Keterangan: Angka yang diikuti oleh huruf yang sama pada baris yang sama menunjukkan tidak berbeda nyata menurut DMRT pada tingkat kepercayaan $95 \%$

\section{Pertumbuhan kale}

Kale mengandung $\beta$-carotene, vitamin $\mathrm{C}$, serat, dan antioksidan (Sikora dan Bodziarczyk 2012). Pertumbuhan kale dipengaruhi oleh jenis media tanaman pada sistem hidroponik (Taofik et al. 2019). Hasil penelitian menunjukkan bahwa semua kale dapat tumbuh dengan baik pada media spons, rockwool lokal dan rockwool impor (Tabel 4). Namun penggunaan jenis media spons, rockwool lokal dan rockwool impor tersebut tidak berpengaruh nyata terhadap semua parameter pertumbuhan kale (Tabel 4).

Tabel 4. Pertumbuhan kale pada tiga media yang berbeda

\begin{tabular}{llrc}
\hline \multirow{3}{*}{ Peubah } & \multicolumn{3}{c}{ Media } \\
\cline { 2 - 4 } & Spons & \multicolumn{1}{c}{$\begin{array}{l}\text { Rockwool } \\
\text { Lokal }\end{array}$} & $\begin{array}{l}\text { Rockwool } \\
\text { Impor }\end{array}$ \\
\hline Tinggi (cm) & $40,2 \pm 1,4$ & $34,1 \pm 0,9$ & $38,6 \pm 0,4$ \\
Jumlah daun & $11,5 \pm 0,6$ & $10,0 \pm 0,5$ & $10,8 \pm 1,0$ \\
Bobot akar (g) & $10,8 \pm 0,5$ & $8,3 \pm 0,5$ & $10,3 \pm 1,0$ \\
Bobot tajuk (g) & $74,0 \pm 1,2$ & $55,5 \pm 1,3$ & $61,0 \pm 1,6$ \\
\hline
\end{tabular}

Pertumbuhan tanaman merupakan proses pembelahan sel, pembesaran sel, dan diferensiasi sel yang berlangsung sepanjang kehidupan tanaman (Ehret et al. 2013). Pertumbuhan tanaman dipengaruhi oleh faktor genetik dan faktor luar. Salah satu faktor luar yang mempengaruhi pertumbuhan tanaman adalah nutrisi dan jenis atau tekstur media tanam yang digunakan (Aires 2018; Wasonowati 2011; Wijaya dan Soeparjono 2014).

Hasil penelitian ini ditemukan bahwa jenis media tanam (spons, rockwool lokal dan rockwool impor) yang digunakan berpengaruh terhadap pertumbuhan kangkung (Tabel 2) dan pertumbuhan pakcoy (Tabel 3). Sebaliknya, jenis media yang digunakan tidak berbeda nyata terhadap pertumbuhan kale (Tabel 4). Hal ini disebabkan karena media tanam menentukan pertumbuhan tanaman (Atif et al. 2016; Perwitasari et al. 2012; Sardoei dan Shahdadneghad. 2015). Respons tanaman terhadap media tidak semua sama yaitu pada tanaman tertentu dapat terjadi adanya interaksi antara varietas tanaman dengan media yang digunakan. Zuyasna et al. (2009) melaporkan bahwa jenis media tanam mempengaruhi pertumbuhan varietas mentimun pada sistem hidroponik. Ditemukan adanya interaksi yang sangat signifikan antara jenis media tanam yang digunakan dengan varietas mentimun pada budidaya dengan sistem hidroponik. Mustofa et al. (2018) melaporkan variasi media tanam antara: bagase, bagase + kerikil, dan bagase + pecahan batu bata berpengaruh terhadap pertumbuhan kubis bunga pada sistem hidroponik. Pertumbuhan tanaman kubis bunga terbaik dihasilkan pada saat digunakan media tanam bagase + pecahan batu bata. Bagase sebagai media hidroponik substrat dengan penambahan pecahan batu bata memberikan hasil pertumbuhan lebih baik. Hasil penelitian ini sesuai dengan Suryani et al. (2017) melaporkan bahwa produksi kultivar kentang Granola Kembang dan kultivar kentang Granola Lembang dipengaruhi oleh jenis media tanam. Berdasarkan penelitian ini digunakan media tanam berupa sekam bakar 100\%, sekam bakar limbah biogas (1:1), sekam bakar limbah biogas (2:1), dan sekam bakar limbah biogas (3:1). Hasil penelitian menunjukkan bahwa media tanam terbaik untuk Granola Lembang adalah sekam bakar limbah biogas (1:1) dan media tanam terbaik untuk Granola Kembang adalah sekam bakar limbah biogas (3:1). Komposisi media tanam pasir kali, arang sekam padi dan serbuk gergaji kayu jati mempengaruhi pertumbuhan tomat yang dibudidayakan secara hidroponik. Komposisi pasir kali: sekam padi: serbuk gergaji kayu jati dengan perbandingan 1:1:2 merupakan media terbaik untuk pertumbuhan tomat (Bachtiar et al. 2017). Perwitasari et al. (2012) juga melaporkan bahwa media tanam yang berbeda menghasilkan pertumbuhan yang berbeda pada pakcoy yang dibudidayakan secara hidroponik.

Dengan demikian maka adanya pengaruh media tanam (spons, rockwool lokal dan rockwool impor) terhadap pertumbuhan kangkung dan pakcoy pada penelitian ini sejalan dengan yang telah dilaporkan bahwa media tanam berpengaruh terhadap pertumbuhan tanaman tertentu (Perwitasari et al. 2012; Bachtiar et al. 2017; Suryani et al. 2017). Namun respons pertumbuhan tanaman berbeda pada semua jenis media tanaman. Hasil penelitian ini pada tanaman kale menunjukkan bahwa penggunaan jenis media (spons, rockwool lokal dan rockwool impor) tidak berpengaruh terhadap pertumbuhan. Telah dilaporkan juga bahwa ada jenis media yang digunakan mempengaruhi pertumbuhan tomat yang dibudidayakan secara hidroponik atau sebaliknya. Telah dilaporkan bahwa ada juga jenis media tertentu yang tidak berpengaruh terhadap pertumbuhan (Bachtiar et al. 2017).

Pertumbuhan kangkung dan pakcoy lebih baik ditemukan pada media spons. Hal ini disebabkan karena spons memiliki porositas yang jauh lebih tinggi dibandingkan dengan media rockwool lokal dan rockwool impor. Porositas media adalah proporsi ruang pori (ruang kosong) media yang terdapat dalam suatu volume media yang dapat ditempati oleh air dan udara sehingga merupakan indikator kondisi drainase dan aerasi tanah. Media yang poros berarti cukup mempunyai ruang pori untuk pergerakan air dan udara masuk dan keluar menjadi lebih leluasa. Telah dilaporkan bahwa media tanam yang memiliki porositas yang tinggi dapat meningkatkan panjang akar lateral dan berat kering tajuk kacang hijau (Kusuma et al. 2013). Peningkatan porositas tanah dapat meningkatkan pertumbuhan bayam (Anastasia et al. 2014). Media tanam hidroponik yang baik adalah media yang memiliki porositas yang baik agar sirkulasi air dan udara 
berlangsung dengan baik di sekitar sistem perakaran tanaman (Gui et al. 2010; Titouna dan Bougoul 2013). Oleh sebab itu, sifat spons yang lebih poros berperan menentukan pertumbuhan kangkung dan pakcoy pada media spons lebih baik dibandingkan pada pertumbuhan di media rockwool lokal dan rockwool impor. Namun, sensitivitas tanaman terhadap sifat porositas tanaman berbeda-beda pada setiap tanaman.

Pertumbuhan kangkung dan pakcoy pada media spons yang lebih baik dibandingkan media rockwool lokal dan rockwool impor merupakan informasi yang baik sehingga spons dapat digunakan sebagai media alternatif. Apabila respons pertumbuhan tanaman sama saja pada ketiga jenis media sudah hal yang baik karena spons harganya jauh lebih murah dibandingkan dengan rockwool lokal dan rockwool impor sehingga dapat menekan biaya produksi. Selain itu, spons lebih mudah ditemukan bahkan banyak spons yang dibuang menjadi limbah lingkungan. Dengan demikian ditemukan potensi spons yang baik sebagai media tanam pada sistem hidroponik diharapkan dapat mengurangi limbah. Keterbatasan dalam mendapatkan media tanaman hidroponik pada suatu lokasi tertentu dapat diatasi dengan menggunakan spons. Pemanfaatan media tanam dengan harga yang murah seperti spons penting agar dapat dijangkau oleh semua lapisan masyarakat.

Alternatif jenis media yang berpotensi baik pada sistem hidroponik perlu terus dikembangkan. Hal ini karena peminat sayur hidroponik terus meningkat sebab sayur hidroponik lebih segar dan lebih bersih dibandingkan dengan sayuran hasil budidaya secara konvensional. Sayuran hidroponik lebih bersih karena tidak bersentuhan langsung dengan tanah serta tingkat serangan penyakit dan hamanya relatif kecil karena pada umumnya dibudidayakan pada rumah kaca atau rumah plastik. Penampilan sayuran hidroponik pada umumnya lebih segar karena nutrisi yang dibutuhkan lebih dapat dioptimalkan. Oleh sebab itu, permintaan akan sayuran tersebut setiap tahun terus meningkat. Terutama di kota-kota besar akibat terbatasnya lahan pertanian maka untuk mencukupi kebutuhan sayuran hidroponik merupakan alternatif yang memiliki potensi yang baik untuk diaplikasikan.

\section{KESIMPULAN}

Spons dapat sebagai alternatif media tanam kangkung, pakcoy dan kale pada budidaya sistem hidroponik. Kangkung dan pakcoy tumbuh lebih baik pada media spons dibandingkan media rockwool lokal dan rockwool impor.

\section{DAFTAR PUSTAKA}

Aires A. 2018. Hydroponic production systems: impact on nutritional status and bioactive compounds of fresh vegetables. In: Asaduzzaman $M$, Asao $T$, editors. Vegetables: importance of quality vegetables to human health. London (UK): IntechOpen. p. 55-66.

Al-Raisy FS, Al-Said FA, Al-Rawahi MS, Khan IA, AlMakhmari SM, Khan MM. 2010. Effects of column sizes and media on yield and fruit quality of strawberry under hydroponic vertical system. Eur J Sci Res. 43(1):48-60.
Anastasia I, Izzati M, Suedy SWA. 2014. Pengaruh pemberian kombinasi pupuk organik padat dan organik cair terhadap porositas tanah dan pertumbuhan tanaman bayam (Amarantus tricolor L.). J Akad Biol. 3(2):1-10.

Atif MJ, Jellani G, Malik MHA, Saleem N, Ullah H, Khan MZ, Ikram S. 2016. Different growth media effect the germination and growth of tomato seedlings. Sci Technol Dev. 35(3): 123-127.

Bachtiar S, Rijal M, Safitri D. 2017. Pengaruh komposisi media hidroponik terhadap pertumbuhan tanaman tomat. BIOSEL (Biology Sci Educ): J Penelit Sci Pendidik. 6(1):52-60.

Badan Pusat Statistik. 2015. Statistik Indonesia 2015. Subdirektorat Publikasi dan Kompilasi Statistik, Statistik Subdirektorat Indikator, editors. Jakarta: BPS - Statistics Indonesia. 670 p.

Bozkurt S, Mansuroğlu GS, Kara M. 2009. Responses of lettuce to irrigation levels and nitrogen forms. African J Agric Res. 4(11):1171-1177.

Dias JS. 2012. Nutritional Quality and Health Benefits of Vegetables: A Review. Food Nutr Sci. 03(10):13541374. http://dx.doi.org/10.4236/fns.2012.310179.

Ehret DL, Usher K, Helmer T, Block G, Steinke D, Frey B, Kuang T, Diarra M. 2013. Tomato fruit antioxidants in relation to salinity and greenhouse climate. J Agric Food Chem. 61(5):1138-1145. https://dx.doi.org/10.1021/jf304660d.

Gui X, Cao A, Wei J, Li H, Jia Y, Li Z, Fan L, Wang K, Zhu H, Wu D. 2010. Soft, highly conductive nanotube sponges and composites with controlled compressibility. ACS Nano. 4(4):2320-2326. https://dx.doi.org/10.1021/nn100114d.

Haghighi M, Barzegar MR, da Silva JAT. 2016. The effect of municipal solid waste compost, peat, perlite and vermicompost on tomato (Lycopersicum esculentum L.) growth and yield in a hydroponic system. Int J Recycl Org Waste Agric. 5(3):231-242. https://dx.doi.org/10.1007/s40093-016-0133-7.

Kusuma AH, Izzati, Saptiningsih E. 2013. Pengaruh penambahan arang dan abu sekam dengan proporsi yang berbeda terhadap permeabilitas dan porositas tanah liat serta pertumbuhan kacang hijau (Vigna radiata L.). Bul Anat Fisiol. 21(1):1-9.

Manchali S, Chidambara Murthy KN, Patil BS. 2012. Crucial facts about health benefits of popular cruciferous vegetables. J Funct Foods. 4(1):94-106. https://dx.doi.org/10.1016/j.jff.2011.08.004.

Mulyani A, Kuntjoro D, Nursyamsi D, Agus F. 2016. Konversi lahan sawah indonesia sebagai ancaman terhadap ketahanan pangan. $\mathrm{J}$ Tanah Iklim. 40(2):121-133.

Mustofa AI, Purnomo D, Sakya AT. 2018. Pertumbuhan dan hasil kubis bunga pada sistem hidroponik substrat dengan media bagase. Agrotechnology Res J. 2(1):610. https://dx.doi.org/10.20961/agrotechresj.v2i1.17342.

Nguyen NT, Mclnturf SA, Mendoza-Cózatl DG. 2016. Hydroponics: A versatile system to study nutrient allocation and plant responses to nutrient availability and exposure to toxic elements. J Vis Exp.(113):1-9. https://doi.org/10.3791/54317. 
Nugraheni FT, Haryanti S, Prihastanti E. 2019. Pengaruh perbedaan kedalaman tanam dan volume air terhadap perkecambahan dan pertumbuhan benih sorgum (Sorghum bicolor (L.) Moench). Bul Anat Fisiol. 3(2):223-232.

Perwitasari B, Tripatmasari M, Wasonowati C. 2012. Pengaruh media tanam dan nutrisi terhadap pertumbuhan dan hasil tanaman pakchoi (Brassica juncea L.) dengan sistem hidroponik. Agrovigor $\mathrm{J}$ Agroekoteknologi. 5(1):14-25.

Radhakrishnan G, Upadhyay TK, Singh P, Sharma SK. 2019. Impact of hydroponics: present and future perspective for farmer's welfare. Suresh Gyan Vihar Univ Int J Environ Sci Technol. 5(2):19-26.

Ramya V, Patel P. 2019. Health benefits of vegetables. IJCS. 7(2):82-87.

Roidah IS. 2014. Pemanfaatan lahan dengan menggunakan sistem hidroponik. J Univ Tulungagung Bonorowo. 1(2):43-50.

Sardoei AS, Shahdadneghad M. 2015.Effect of different growing media on the growth and development of Zinnia (Zinnia elegans) under the agro-climatic condition of Jiroft. Res J Environ Sci. 9(6):302-306.

Sikora E, Bodziarczyk I. 2012. Composition and antioxidant activity of kale (Brassica oleracea L. var. acephala) raw and cooked. Acta Sci Pol Technol Aliment. 11(3):239248. http://www.ncbi.nlm.nih.gov/pubmed/22744944.

Suryani L, Susila Putra ET, Dianawati M. 2017. Pengaruh komposisi media tanam hidroponik agregat terhadap produksi benih G0 tiga kultivar kentang (Solanum tuberosum L.). Vegetalika. 6(2):1-3. https://doi.org/10.22146/veg.26166.

Taofik A, Frasetya B, Nugraha R, Sudrajat A. 2019. The effects of subtrat composition on the growth of Brassica oleraceae Var. Achepala with drip hydroponic. J Phys Conf Ser. 1402(3):033031. https://doi.org/10.1088/1742-6596/1402/3/033031.
Titouna D, Bougoul S. 2013. Resolution of the richards equation for the water transport in a growing substrate. Energy Procedia. 36:915-922. https://doi.org/10.1016/j.egypro.2013.07.105.

Umar KJ, Hassan LG, Dangoggo, SM, Ladan MJ. 2007. Nutritional composition of water spinach (Ipomoea aquatica Forsk.) Leaves. J Appl Sci. 7(6):803-809. https://doi.org/10.3923/jas.2007.803.809.

Wahome PK, Oseni TO, Masarirambi MT, Shongwe VD. 2011. Effects of different hydroponics systems and growing media on the vegetative growth, yield and cut flower quality of gypsophila (Gypsophila paniculata L.). World J Agric Sci. 7(6):692-698.

Wallace TC, Bailey RL, Blumberg JB, Burton-Freeman $\mathrm{B}$, Chen $\mathrm{CO}$, Crowe-White $\mathrm{KM}$, Drewnowski A, Hooshmand S, Johnson E, Lewis R, Murray R, Shapses SA, Wang DD. 2020. Fruits, vegetables, and health: A comprehensive narrative, umbrella review of the science and recommendations for enhanced public policy to improve intake. Crit Rev Food Sci Nutr. 60(13):2174-2211. https://doi.org/10.1080/10408398.2019.1632258.

Wasonowati C. 2011. Meningkatkan pertumbuhan tanaman tomat (Lycopersicon esculentum) dengan sistem budidaya hidroponik. Agrovigor J Agroekoteknologi. 4(1):21-27.

Wijaya KA, Soeparjono S. 2014. Efek suplai nitrogen terhadap kadar gula nira tebu varietas bululawang. AGRITOP. 12(2):109-112.

Yang U-J, Ko S, Shim S-M. 2014. Vitamin C from standardized water spinach extract on inhibition of cytotoxicity and oxidative stress induced by heavy metals in HepG2 cells. J Korean Soc Appl Biol Chem. 57(2):161-166. https://doi.org/10.1007/s13765-013-4187-1.

Zuyasna Z, Zaitun Z, Alfina S. 2009. Pertumbuhan dan hasil tiga varietas mentimun (Cucumis sativus L.) pada medium hidroponik tertentu. J Agrista. 13(3):104-112. 